\title{
To the Question of the Destructed Rock Mass Movements Regime Assessment
}

\author{
KHARKOVSKYI Victor S. ${ }^{1}$, PLOTNIKOV Valery M. ${ }^{1}$, KOMLEVA \\ Eugenia V. ${ }^{1}$, KOGAY Olessya A. ${ }^{1}$, KOROBKINA Anna S. ${ }^{2}$, HARLAMOVA \\ Anna V. ${ }^{3}$, GONCHAROV Yuri N. ${ }^{4}$, BALIKBAYEV BekturKh. ${ }^{4}$ \\ (1.Karaganda State Technical University, Mining Faculty, The department of "Mine \\ aerology and a labor safety" 100027, Karaganda, Kazakhstan;2.Karaganda State \\ Technical University, Mining Faculty, Methodist of International office 100027, \\ Karaganda, Kazakhstan;3.Karaganda Research Institute of Industrial Safety, \\ Branch corporation 100027, Karaganda, Kazakhstan; 4.JSC"EEC" \\ "Vostochniyt",141202,Ekibastuz,Kazakhstan)
}

\begin{abstract}
The article proposed equation criteria specifying the interaction force field with the medium. Based on the proposed regularities we suggested the medium parameters changes dependences and momentum and energy characteristics, the resistance of the medium on which the formation hazards equation were made. A device for rock mass overloading in a large volume, with a reduction of the hazards emission into working zone by two rates was suggested.
\end{abstract} Key words: cargo flow, safety criteria, the conveyor unit, the porosity of the medium, the flow state, fluent.

\section{Introduction}

International practice recommends conveyor transport for conditions of high power open pit mineral deposits. Advantages are threading movement of raw materials, a relatively large length of transportation, the ability of bulk material movement angle to $20^{\circ}$ which allows reducing the delivery path compared to rail and automobile road 6-8 and 3-4 times, increase the height of the mining face and apply the technique of greater productivity. However, at the same time there is an increase of shattered rock mass hazards allocation and creation of the emergency conditions of intermediate filling containers intended for the localization of the active technological processes components: dust, gases, radioactive substances, and the like. For solid and liquid mineral output hazards emission accompanied by a translation of the raw material definitions in special aerodynamic condition-aerosol, which manifests overload destroyed the rock mass and generates dust flow, the concentration of dust in the working area is greater than $5,000 \mathrm{mg} / \mathrm{m} 3$, which determines the optimal flow regime movement of destroyed rock mass.

\section{Characteristic of the work}

Criteria setting for technical process evaluating safety is a major engineering challenge and requires the linking of a random process measure probability in the settlement periods and volumes of production, based on the indicators of the kinetics and medium resistance to external effects, i.e. regularities

$$
\begin{gathered}
\frac{\text { Эк }}{\mathrm{J}}=R \\
R=2 U_{\mathrm{g}}
\end{gathered}
$$

where $Э \kappa$ - the kinetic energy of the external load power ; $\mathrm{J}$ - the pulse impact on the medium; $R$-resistance of the medium, estimated as twice the value of the dynamic speed; $2 U \mathrm{~g}$ - dynamic flow rate . 
These dependences $\left.{ }^{[1,} 2\right]$ determine the movement of the medium elements to considered conditions of destroyed mountain mass or fluent, conventional liquid filling volume of space, determining fine particles emissions beyond transported stream.

If the technological system is physical and chemical or a similar space, the arrangements for the transfer of energy and mobility of elements determined by the laws of Einstein and has the form shown as ${ }^{[2,7,8]}$

$$
\begin{gathered}
D=a T \\
a=\frac{1}{b}
\end{gathered}
$$

Where $D$ is thediffusion coefficient, medium circulation characteristics, the mobility of the considered element, the internal friction of the received energy level; $T$ is the energy of the medium mobility; $b$ is the binding energy between the elements of the medium;

$a$ is the medium mobility.

In this case, the analyzed environment should be considered as a multi-phase, skeleton forming pseudo-solid and pseudo-liquid and at its mobility level determining the system destruction.

$$
a_{f}=\frac{\beta_{1} k\left(1-m_{0}\right)}{1-\beta_{1} k\left(1-m_{0}\right)}
$$

Where $k\left(1-m_{0}\right)$ - all-round medium compression module; $m_{0}$-the porosity the system; $\beta$-dimensionless parameter characterizing the volumetric change of medium(index 1 belongs to solid, index 2 belongs to liquid).

In the submission of Y. I. Frenkel ${ }^{[9]}$ parameter $a_{f}$ characterizes a disturbance of porosity defining fluent mobility (viscous fluid) and in apparently solid phase in motion relative to the standard.

Established $^{[3,9]}$ for rocks during compaction within $0,92-0,72$ sample and its physical parameters, as the all-round compression modulus is constant.

For these conditions, shattered rock mass displacements estimated according to the condition of double phase medium compressibility characterized with deformation of shattered rock mass volume with the bulk material parameters characteristics.

For the analyzed conditions the failure of small particles and transfer them into aerosol produced by the deformation of the destroyed rock mass and vortex fluent diffusion. Therefore, based on the conditions of disclosure concept of "dynamic speed" [1, 2, 4, 6-9] we have regularity

$$
\sqrt{\frac{\tau}{\rho}}=\Gamma \mathrm{KK}
$$

Where $\tau$-displacement of medium tension; $\Gamma$ - fluent circulation; $\mathrm{K}_{\kappa} \quad-$ coefficient of rolling friction.

Depending on the specific conditions of external force field adopted equation engineering calculations for the assessment of the circulation can be estimated by the following fluent indicators: kinematic viscosity, diffusion coefficient, index of medium thermal conductivity.

Circulation, or rather its analogues, concrete medium fluent: viscosity, diffusion, thermal diffusivity, i.e. reverses flow characteristics:

$$
\Gamma=\frac{3 \sqrt{2} \pi d_{2}^{2}}{J_{i}}
$$

Where $d_{2}$ is the surface characteristic of the pore space vortex, the size of the pore volume (solid) ; $J_{i}$ is the pulse impact of an external force field to the unit volume of destroyed rock mass pore space (liquid).

Studying the conditions of mass transfer V. M. Casey ${ }^{[4]}$ proposed the characteristic of an external force field its impulse 
component and circulation as a criterion for the liquid substances transfer - to be Lewis criterion in particular:

$$
\frac{\omega d n}{v}=L e
$$

Where $\omega$ is the frequency of the force field impact; pulse characteristic of the fluent; $v$ is kinetic viscosity of the medium.

This allows determining the pattern of the force field impact on the porous medium with following dimensionless equation:

$$
\mathrm{Re} \cdot \mathrm{Sh} \cdot \mathrm{Le}=2
$$

where $S h$ is Strouhal number, stationary criterion of the homochromatic process; Re is Reynolds number, friction regime of the destroyed rock mass.

The characteristic mode of transportation destroyed mass flow gets the main interests. In general, the evaluation of the flow binding is determined by slit distance between its elements, i. e.

$$
\operatorname{Re}=\frac{u_{n} d_{1}}{v_{2}}
$$

where $U n$ is the flow rate.

For the conditions of small fractions transfer, the determining factor is the shown size of the destruction elements separation, i. e. the condition of the slit formation, which was laid to the evaluative indicator, the regularity takes the following form:

$$
\frac{d_{2}}{d_{1}}=\frac{v_{2} r_{e}}{u_{n}}
$$

Set at a value of Reynolds number up to 10 - the mode of destroyed rock mass movement is connected; from 10 to 2100 is transitional and when the number is bigger than 2100 - elements of destruction have no connection with each other.

For the connected mode defines the air conditions:

$$
\frac{d_{2}}{d_{1}} \leq 0.01
$$

Strouhal criterion is a characteristic established traffic type and represents the flow rate conditions change for a certain period of time.

$$
S h=\omega^{2} d_{2} / \mathrm{Un}
$$

The assessment index can be taken for the continuous mode $-0,12$, intermediate - 0 , 16 , turbulent - 0,21

Transfer of energy and matter with moving means (liquid or gaseous) in the criteria form of theoretical developments, criterion $[4,7,9,10]$, proposed to make according to the following dependence evaluation criterion:

And to the account of aerosol stream movement according to the theory of mass transfer ${ }^{[4]}$ determined by the condition:

$S t \cdot \operatorname{Re} \cdot \operatorname{Pr}=4.364$
Where $S t-$ Stanton number
characterizes the fluent friction
conditions and skeleton forming space -
the hydraulic friction coefficient; Pr- the
assessment conditions of transferring
energy level of sliding friction into
rolling friction (fluent physical
characteristics).

Stanton criterion characterizes the loss of energy to overcome friction.

$$
S t=0.5 \cdot C f
$$

where $\mathrm{C} f$ is the local friction index.

Prandtl number is determined by the fluent medium and characterized by its physical properties for the analyzed conditions - air.

$$
\operatorname{Pr}=\frac{v}{a}
$$

Where $a$ is thermal diffusivity.

All this allows dependences [9] and [14] combine into the system of the destroyed rock mass displacement regime criteria assessment. 


$$
\left\{\begin{array}{l}
\mathrm{Re} \cdot \mathrm{Sh} \cdot \mathrm{Le}=2 \\
\mathrm{St} \cdot \mathrm{Re} \cdot \mathrm{Pr}=4.364
\end{array}\right.
$$

Which can divide the overload into three zones (or rather the conveyor unit) gutter, and a lower receptor, produce their aerodynamic separation and determine the optimal stream location in each of them.

Experiments of condition $[1,3,5,6$,$] the$ smallest emission of dust into working area occurs in a shattered rock mass laminar movement, at a high speed of bulk material movement it is necessary to remove the gutter from the unloading head of the upper conveyor, height separation assessment of the gutter and a lower belt destruction which are measured by the system (17).

These defined features determine the localization of the resulting hazards technological processes.

On this basis, the reloading device was developed entered in force on the territory of the section "Vostochniy" JSC "EEC" [5]: Performance 600-1500 t / h; Height overload 4-6 m; cargo flow moving horizontally $4 \sim 6 \mathrm{~m} / \mathrm{s}$; the average size of shattered rock mass $300 \mathrm{~mm}$; belt width $-2 \sim 4 \mathrm{~m}$.
The degree of dust aerosol emission referenced to the conveyor unit is determined by the condition of reloaded material contact with the medium a confined structure space.

Thus, the disruption of particles occurs from the contiguity surface of the contact layers. Consequently, the layer mode, which the new conveyor unit was designed for, characterized by a minimum aerosol output because the contact is only possible on the top. At the free pieces fall in the shelter the disruption is made from the surfaces oriented toward reloaded material fall, which significantly increases the large fractions aerosols output, which is typical for dust settling chambers ${ }^{[6]}$.

Applied conditions of adopted reload the boundary layer thickness does not exceed $0.027 \mathrm{~mm}$, which corresponds to the particle size $20 \mathrm{~km}$.

The device worked for more than two years in the process chain without emergency. The characteristics of working places dustiness in the comparative assessment of the project device operation in comparison with regulated by KSTU professionals, is shown in table 1.

Table 1: Comparative assessment of the device operation, recommended by KSTU professionals and design

\begin{tabular}{|l|l|l|l|l|}
\hline \multirow{2}{*}{ The device type } & \multirow{2}{*}{$\begin{array}{l}\text { Measuring } \\
\text { area }\end{array}$} & \multicolumn{3}{|c|}{ Dustiness, $\mathrm{mg} / \mathrm{m}^{3}$} \\
\cline { 3 - 5 } & Bottom & 7900 & 6123 & 5480 \\
\cline { 2 - 5 } & Top & 4330 & 3686 & 3252 \\
\hline \multirow{2}{*}{ Nesign } & Bottom & 25,6 & 15,03 & 6,7 \\
\cline { 2 - 5 } & Top & 20,6 & 12,24 & 5,5 \\
\hline
\end{tabular}

1. The equation of the criteria assessment

Table 1 shows that the calculation of all patterns allows to manage the process by which hazards are formed and have access to the work zone, herewith the concentration of dust was reduced by more than two rates.

\section{Conclusion}

The abovementioned results allow the following concluding: process is proposed for technological processes safety assessment based on the external energy arrangement, impulse characteristics response and resistance of medium.

2. The regularities of medium features change were shown due to the fundamental features of the material and fluent. 
3. Implementation of the received recommendations will reduce the hazard emission on example of dust aerosols by more than two rates.

\section{References}

[1] Methods of advanced coalbed dust formation reduce / A. E. Perezhilov, E. Y. Dikolenko, V. S. Kharkovskiy, etc. M.: Nedra, 1995, p.408

[2] Metodology of Manufacturing Hazards and Rates Assessment/ Viktor S. Kharkovskiy, Valeriy M. Plotnokov, Nicolay A. Drizhd, Evgeniya V. Komleva, Anna V. Kharlamova 'Europen Researcher' № 1-14 August 2012.

[3] O. V. Abramov, A. N. Rosenbaum Prediction of the technical systems state. M.: Science 1990, p.126

[4] V. M. Case Convective heat and mass transfer. M.: Energy 1972, p.448
[5] Patent number $27023 \mathrm{KZ}$ A4V62 69/18 (2006.01)

[6] Satarin V. I., Purley S. B. Movement and dedusting gases in the cement industry. M.: Gosstroiizdat, 1960, p. 305 [7] L. D. Landau, E. M. Lifshitz Theoretical Physics. T. Hydrodynamics VI - M.; Science 1986 - 736 p.

[8] The rheology. Theory and Applications / F. Eirich, A. Bondi, P. A. Rebinder and others. M.: publishing house Inlit 1962. p. 387-491, 459-508, 812-818.

[9] Mechanic of saturated mountain mediums / V. I.Nicholas, K. S. Basniev, A. T. Gorbunov, G. A. ZotovNedra 1970 p. 239.

[10] L. G. Loitsyansky Fluid and gas mechanics. - M.: Science, 1973, 547p. 